\title{
Hindrance of ICT Adoption to Library Services in Higher Institution of Learning in Developing Countries
}

\author{
Fredrick Mzee Awuor ${ }^{1,2, *}$, Kefah Rabah ${ }^{2}$, Benard Magara Maake ${ }^{1,2}$ \\ ${ }^{1}$ Kisii University, P.O. Box 408 Kisii, 40200, Kenya \\ ${ }^{2}$ Jaramogi Oginga Odinga University of Sci \& Tech. P.O. Box 210 Bondo, 40601, Kenya \\ *Corresponding Author: fredrickawuor@gmail.com
}

Copyright (C) 2013 Horizon Research Publishing All rights reserved.

\begin{abstract}
The adoption of ICT has revolutionized service provision in libraries and their general information management systems. This has transformed most services to digital: e-database (e-resources), e-catalogs, e-library and use of archiving technology like DSpace. Today, within the developing world, most libraries are moving towards transforming their existing traditional library services to digital systems - allowing them to tap and benefit from the vast advantages of ICT, for example, operation costs reduction, increased efficiency, an on-the-fly availability of information. Even with such numerous benefits, most Higher Institutions of Learning (HILs) in developing countries still lag behind on adoption of ICT in their library services. This paper seeks to investigate the challenges that hinder the adoption of ICT in libraries with special attention to HILs in developing. Further, solutions and recommendations to address these challenges are presented with case study analysis.
\end{abstract}

Keywords ICT, Library Information Management (LIM), Developing Countries, Higher Institutions of Learning (HIL)

\section{Introduction}

The rapid development in Information and Communication Technology (ICT) infrastructure across the globe has led to transformation in the way we manage information in the information age. ICT is broadly defined as a diverse set of technological tools and resources used to communicate and create, disseminate, store, and manage information[1]. The library as a source of knowledge has not been spared -- today, technology has transformed Library and Information Centres such that they have to adapt to these transformation to be able to address end users' ever growing expectations and dynamic needs. Moreover, the 21st century has ushered our society into the information age -where we're witnessing an unprecedented paradigm shift in the rendering of library and information services worldwide.
The ripple effect of the influence of ICT on every aspect of human endeavour remains colossal and its impact on library and information services has not been exclusive[2, 3]..

Furthermore, the rapid transformation of the ICT infrastructure has created new opportunities and challenges for traditional libraries such that the new trend is to move towards digital collection. Existing libraries are busy digitizing their traditional collections via online subscriptions and planning, design, deployment and ongoing operations management and technical support of ICT infrastructure [4].

The Information Age is characterized by new ways of information generation, managing, and dissemination using ICT. Today, ICT has revolutionized service provision in all sectors of the economy including education via increase in access to knowledge. Example of such ICT service is Open Distance Learning (ODL) System or eLearning, which has rapidly become a major element in pursuing higher education opportunities; an increase in the number of unique environment where educational opportunities are offered [5]. eLearning refers to using ICT oriented services to provide leaning and training that is dynamic (anywhere and anytime) on an Internet platform. Today Africa is the most dynamic eLearning market on the planet. Ambient Insight has revised its forecasts significantly upward for most African countries. The growth rate for self-paced eLearning in Africa now stands at $15.2 \%$ and is projected to increase substantially over the coming years. Revenues reached US \$250.9 million in 2011 and will more than double to US $\$ 512.7$ million by 2016. Eleven of the sixteen countries analyzed in this region have growth rates above the $15.2 \%$ aggregate rate. Senegal has the highest growth rate in Africa at $30.4 \%$, followed by Zambia, Zimbabwe, and Kenya at $27.9 \%, 25.1 \%$ and $24.9 \%$, respectively. Revenues are growing very fast in many African countries. By 2016, revenues will double in seven countries and will more than triple in four countries (AIR, 2013 B).

This massive increase in access to education needs to be matched by equal increase to library funding, ICT infrastructure, resources and services at locations other than main campuses; an increased concern and demand for 
equitable service for all students in higher education, no matter where the classroom may be; a greater demand for library and information services by faculty and staff at remote learning sites [6,7]. For the Libraries, ICT's has tremendously changed the Management of Resources or House Keeping Operations as well as the way services are delivered. In the specific context of Library Information Services (LIS), one of the implications of use of ICT is that Libraries can reach out globally to provide their services 24-hours a day in very cost effective manner. ICT has enabled users to avail many services without any human intervention, the role of LIS professional is changing from an intermediary to a facilitator and enabler[8].

This impact of ICT on library and information services has led to the development of new professional paradigms within the field of librarianship i.e., meeting the students' needs in fulfilling course assignments and thereby enriching academic programs; meeting teaching and research needs; facilitating the acquisition of lifelong learning skills; and accommodating other informational needs of the distance learning community as appropriate. This is in contrast to traditional library services where the students go to the library to access the range of information services that they need to satisfy their learning requirements. The introduction of social networking: chat rooms, email services, list-servs, fee based or free online databases and reference services have transformed the usage of traditional library to support distance studies and open access such that the students (and staffs) can access the library anytime anywhere whenever they need the services. Since ICT has eliminated the distance between library services and students we can only achieve quality education if ICT adoption in library services is properly and exhaustively deployed [7].

Academic libraries in the developing nations play an essential role in terms of supplying society with knowledge and information, as well as being considered an inseparable part of the academic provision. These libraries strive to satisfy a strategic academic mission, which includes positively shaping the goals of academic programmes as well as the general information needs of the community [9]. But even as many academic libraries in developing countries strive to incorporate ICT in library services, there are several factors such as financial constraints, technological factors, human factors, cultural factors among others that need to be addressed. Ghuloum et al in [9] argue that a significant lack of ICT related services in libraries can also be attributed to shortage of qualified staff in these libraries. This paper aims to investigate the challenges facing the implementation of ICT solutions in HILs in developing countries and provides practical solutions (and recommendations) to the problems

The rest of the paper is organized as followed: Section II provides an overview of ICT utilization in libraries in developing countries, Section III addresses the challenges and hindrances to ICT diffusion in these libraries while section IV focuses on recommendations to address the bottlenecks discussed in the previous section. Finally, Section V concludes the paper.

\section{Overview of ICT Utilization in Libraries in Developing Countries}

The use of ICTs in libraries in the provision of access to information resources and services is resulting in the disappearance of the concept of a library as has been known for centuries - a physical building located in a specific geographic location. ICT has transformed the nature of library services over a period of time. Library "collections" consist not only of physical information resources such as books, periodicals, videos, films, and many more, stored in physical library buildings. They now include digital resources created locally and those accessed over the Internet from computers that are managed by other libraries or information service providers. Further, unlike in a print-based library system, access to digital information resources is not restricted to specified hours and days of the week at one physical library building. Information resources and services are available 24/7, throughout the year from any computer connected to the Internet from any place around the world [10].

The importance of ICT in libraries particularly in HILs cannot be underscored as noted in [4] since ICT enables optimum utilization and sharing of resources among institutions thereby reducing the operational costs. In addition, ICT enables the librarian to concentrate on other tasks such as research and consultancy as it provides opportunities to deploy innovative methodologies to meet the dynamics needs of library users $[5,11]$.

There are several functions and activities that libraries have been performing which can now be done better using ICTs and at the same time there are others that previously were difficult or impossible to carry out which are now possible as a result of ICTs. Today, there are tremendous opportunities presented by ICTs to libraries $[6,10]$. Some of the important changes that developments in ICT have brought about in information services are [5, 8]:

- Changes in formats, contents and methods of production \& delivery of information products, and a new business model for use of information products. This requires procedural and infrastructural changes and cost implications in Libraries.

- Emergence of Internet as the largest repository of information and knowledge.

- Extinction or significant transformation of some of the conventional information services such as press clippings, contents pages, company information etc.

- Use of new tools and technologies for dissemination of information.

- Transformation of role of LIS professional as the subject specialist and end-user gets directly involved in the information work and consequent need for new skills.

- Shift from physical to virtual services that offer convenience of time and location for access to services.

- Institutional repositories (digital local content e.g., 


\section{digital repositories) \\ - Capacity building}

Library is the heart of the learning community, providing a place for students and faculty to do their research and increase their knowledge [9] and therefore the future of any academic library greatly hinges on its ability to embrace and leverage the potentials of ICT facilities at all levels of their business activities and strategies systems [12, 13]. Though ICT has led to new higher education learning models such as ODL, electronic learning and blended learning that has provided a good opportunity to learn at any time and place, there have been a number of factors that have impeded the large scale uptake of ICT in HILs. These have included such factors as lack of funding to support the purchase of the technology, lack of training among established teaching practitioners, lack of motivation and need among teachers to adopt ICT as teaching tools $[12,13]$.

Today, libraries are using ICTs, especially the Web, to implement online based bibliographic or library use (library literacy) programmes targeting their clients. Among others, these programmes include online or CD-ROM based tutorials on searching online resources and virtual tours of library collections, and these are mainly accessed on intranets, extranets or the Internet. Moreover, use of ICTs enables libraries to avoid problems associated with the use of lecture-based approaches or library orientation programmes. Problems such as dealing with large numbers of students or having a shortage of staff to deliver the programmes or too little time to deliver so much information to students. In addition, ICTs offer students an opportunity to follow the programmes at their own pace in their own time [14].

\section{Hindrance to ICT Diffusion in Libraries in Developing Countries}

Chinwe, et al in [15] points out that ICT use for library operations and services requires library practitioners who are highly skilled both in the traditional library operations and high level of computer literacy, besides being committed and flexible librarians, who are ever ready to engage in sustained reasoning and can manage complex situations.

In [9], the authors point out that libraries in HILs have not been given key attention that they deserve in terms of financial allocations -- thus limiting their ability to meet the targeted requirements of supporting the learning process positively. The libraries are, therefore, not able to acquire adequate ICT services (e.g., access to computers, copies, printers, network/internet and subscriptions to more electronic databases, modern bindery equipment etc.). Technological factors, such as ICT illiteracy is also a bottleneck since many library users in developing countries are not able to utilisation ICT services and their applications in library hence there in need for consistent user training and user support services [5]. Moreover, most of the staffs in the academic libraries in these countries need more experience and training to deal with ICT services as illustrated by (Bader, 2008) in [9]. Research carried out in [6] shows that some developing countries consider a library as "some place to store books" rather than the key component of academics and research activities. Thus, there is a large segment of society and the decision-makers in government in developing countries who do not understand the critical role that a modern academic library could play in developing the economy of a nation.

Here, we'll attempt to present some of the challenges hindering the diffusion of ICT in libraries in HILs, these are: Political and economic instability in developing countries have negatively impacted the operations of libraries in HILs with external funding agencies taking advantage of this instability to push for their own agenda and priorities[6]. The research carried in [16] also reports that the rapid growth of student populations has provided enormous challenges to the HILs since the financial support for these institutions have not kept pace with increasing levels of students enrolment \&growth. Without substantial support from the government and, in some instances, and the inability to charge tuition fee, universities are struggling to provide the necessary and essential services. More-so, in most cases, there is complete lack of physically facilities adequate enough to provide education and services for all the students. It's not uncommon to come across lecture halls, hostels, and libraries that are overcrowded with students.

Notably, and in most cases, there is a complete lack of exposure of library staff to international standards and best practices; experience is also a hindrance factor to adoption of ICT in HILs. Most librarians have never have opportunities to attend conferences outside the region and, therefore, have limited access to cutting-edge knowledge -- such that the library staffs develop internal standards unaware of the existence of international standards [11, 17]. Inadequate access to technical expertise i.e., ICT department, that is responsible for the installation, development and expansion of the backbone network (WLAN/LAN) in the institution and in the library has undermined diffusion of ICT in these libraries. Such a team is required to have basic training in troubleshooting skills and support of library hardware and software[12].

The outdated and bureaucratic procedures in acquisition of ICT equipment and materials coupled with lack of appropriate policies to support development of ICT in HILs is noted to slow down implementation of ICT in developing countries libraries [6].Inadequate diffusion of ICT in library and information centres can also be attributed to lack of real awareness about the benefits of ICT, and the implications if ICT is not integrated in the library's operations [18]. Moreover, Tasubira et al in [18] argues that there is a mindset, fear, and consequent unwillingness to face the changes from the highest decision making levels to the lowest operational levels making libraries and information centres to be uncommitted to joining the information and knowledge society. The process of transforming and integrating ICT in libraries services is a new area in most developing countries and the question of how to adopt it in 
these institutions is yet to be addressed. HILs need to develop local expertise to plan and manage the change and adoption of ICT in libraries

\section{Digital Library and Archives}

Many Libraries traditionally have been repositories of local information and heritage documents such as manuscripts, rare books, maps, photographs and paintings etc. Archives or record management is also part of LIS function, particularly in business and research organizations. In other cases such as university libraries, documents generated in-house such as dissertation and theses, research reports etc represent the intellectual strength of the institution. Libraries are developing digital repositories of such resources, and providing Internet or intranet access to these. Large public and academic libraries also provide up to date local information via internet. Digital libraries are a natural progression from electronic document sharing. The main benefit of digital library is the ability to provide 24-hour, remote access to high-demand or restricted materials for multiple concurrent users. Setting up a digital library can either be done using 'off-the-shelf' digital library products, document management products or library management products capable of digital library management; or in-house system development using open archives software $[5,8]$. Some of the off-the-shelf products are from Blue Angel Technologies, CONTENTdm, Crossnet Systems Ltd, Endeavor Information Systems, Epixtech, ESP, ExLibris, Fretwell-Downing Informatics, IBM, Sirsi, and SydneyPlus. Greenstone (http://www.greenstone.org) and DSpace (http://www.dspace.org) are the leading open source digital library management software.

\section{ICT Enabled Libraries in Kenya}

Regarding library environment, the digital movement is yet to take off. In the absence of strong telecommunication channels, the Internet facility is yet to find its success. Financial constraints are the major hindrance for the growth at national, local and organizational levels. As a result the implementation of ICT infrastructure for libraries is not receiving adequate support from their parent body. To-date, majority of libraries in Kenyadoes not have computer facilities, Internet facilities is still a far cry. The print media is still a major source of information in libraries. Majorities of libraries in Kenya will continue to be deprived of digital information if they cannot find a mechanism to acquire such materials and a facility to read them. Sooner or later the management authorities would realize the need of this vital change and start tuning to the present day requirements, i.e., ICT enabled library services.

\section{Recommendations and Way Forward}

In spite of the various efforts being made by most libraries and information centres in developing countries to adopt and use ICTs, there are still numerous issues that they must be assisted and guided to address. Specifically, the central and local governments authorities should provide adequate funding to HILs library services if they are to deploy appropriate ICTs and play an active role in the provision of access to global information resources in their communities[17]. These libraries need to be assisted to develop formal ICT strategy. In a survey by R. Ondari and C. Kitendo in [6], Ondari reports that to take advantage of ICT in the information centres, full automation of circulation control system, online catalogue access, acquisition control, including search of online sources of publications, and online access to booksellers must be embraced. In addition, qualified staffs with up-date skills in managing ICT enabled libraries need to be deployed in these libraries.

Risk management measures are also needed to be put in place through implementation of secure network, for example, antivirus to protect the digital databases, protection against crackers/hackers by installing firewalls at the proxy server. General risk management via backing-up of databases to guard against data lose, protection against general damage due to power failure, natural disaster e.g., flood, and installation of UPS to cope with the erratic power supply experienced in most developing countries. Standby power supplies i.e., generators or solar power are also very critical in these libraries [15]. Lack of a clear perception of how ICT resources can be sustainably managed, the operational risks, and likely escalating costs of poor information resource management is another area where local expertise needs to be developed, in order to ensure reliability and efficiency in library and information service provision [18].

A comprehensive collection development policy for e-resources should be maintained by the libraries, in order to follow a set of standards and best practices for acquisition and management of electronic information resources. There should be specific budget for new resources and the renewal of existing resources. In addition, professional organizations such as the Kenya Library Association and library administrators should organize short-term training programmes for library professionals in computer applications in library and information services, online information retrieval, data processing, electronic publishing, and also software such as Microsoft Office, CDS/ISIS, etc.[12].

Other general recommendations are follows [19]:

- ICT facilities should be made adequately available by institutions administration such that academic staffs can utilize them in their offices and classroom. This is necessary because ICTs are regarded as integral parts of teaching and research in academic institutions and within the communities.

- The national governments and at local authorities levels, should as a matter of priority, fund libraries very well according to the recommendations of 
UNESCO. This will enable them to provide more of these ICT facilities and properly maintain the existing ones.

- Modalities should be set in motion to enable academic staffs to acquire relevant ICT skills through training. This has the tendency of enabling them to enrich their content knowledge through searching for more and new materials, make learning more meaningful and improve students learning outcomes.

- The financial outlay required in procuring ICT facilities is enormous to the extent that individual academic institutions may not be able to provide it alone. It therefore becomes imperative for these HILs to enter into partnership with such ICT providing organizations as AfriHUB, Zinox, SocketWorks and BusyNet for the purpose of equipping their institutions with ICT facilities. This will enable the academic staffs to acquire necessary ICT skills in order to enhance the quality of their instructional service delivery.

\section{Conclusion}

ICT has changed the work of libraries and information centres as users' demand and expects better and efficient services i.e., electronic/ online resources and databases, ODL among others. Libraries in HILs in developing countries have gotten itself in a situation where they must embrace ICT in order to remain relevant and also meet future challenges. However, these libraries are experiencing a lot of barriers in adoption of ICT resulting from several factors but majorly inadequate funding, and here is where we expect the governments to meet their obligation to provide libraries with adequate funding - noting that is source of knowledge and an enabler of economic growth. In the future work, we'll investigate the contribution of internet and library websites to improving service provision in these libraries.

\section{REFERENCES}

[1] Blurton C., "New directions in education," in UNESCO's World communication and information 1999-2000, ed Paris: UNESCO, 1999, pp. 46-61.

[2] Sridhar M.S, "Skill requirements of LIS Professionals in the new e-world," Library Science with a Slant to Documentation and Information and Information Studies, vol. 36, Jan 5, 20081999.

[3] Igun S.E., "Human capital for Nigerian libraries in the 21st Century," Library Philosophy and Practice, vol. 8, pp. 1-4, 2006.

[4] Sharma P., et al., "Approach To ICT in Library Training, Education and Technology : Issues and Challenges," presented at the ICAL, 2009.

[5] Chauhan B.P., "ICT Enabled Library and Information Services," presented at the Winter School on ICT Enabled Library \& Information Services, Thapar Institute of Engineering \& Technology, Patiala 2004.

[6] Chisenga J., Ed., The Use of ICTs in African Public Libraries: A survey of ten countirs in anglophone Africa. International Network for the Availability of Scientific Publications (INASP), 2004, p.`pp. Pages.

[7] Maurya R.J. and Kumar S., "Using ICT in ODL System for Providing Library and Information Services," in 6th International CALIBER-2008, University of Allahabad, Allahabad, 2008.

[8] Chauhan B.P., "Winter School on ICT Enabled Library \& Information Services," presented at the TIET Patiala, 2004.

[9] Ghuloum H. and Ahmed V., "The Implementation of New ICT Services in Kuwaiti Academic Libraries," The Built \& Human Environment Review, vol. 4, pp. 74-86, 2011.

[10] Chisenga J., "Information and communication technologies: opportunities and challenges for national and university libraries in Eastern, Central and Southern Africa," in Standing Conference of African National and University Libraries of Eastern, Central and Southern Africa (SCANUL-ECS), Dar es Salaam, 2006.

[11] David L.T. (2001). ICT for library and information professionals: a training package for developing countries.

[12] Shariful I.M. and Nazmul I.M., "Use of ICT in libraries: an empirical study of selected libraries in Bangladesh," Library Philosophy and Practice, 2007.

[13] Nazmul I.M. and Shariful I.M., "Information and Communication Technology in Libraries: a new dimension in librarianship," Asian Journal of Information Technology, vol. 5, pp. 809-817, 2006.

[14] Siddike M.A.K., et al., "The adoption of information and communication technology (ICT) in the university libraries of Bangladesh: an exploratory study," in International Seminar "Vision 2021: the role of libraries for building digital Bangladesh” 2011, pp. 153-164.

[15] Chinwe V.A, et al., "The adoption of ICT for library and information services," ed, 2011.

[16] Kellerman, "Title," unpublished|.

[17] Haliso Y., "Factors Affecting Information and Communication Technologies (ICTs) Use by Academic Librarians in Southwestern Nigeria," Library Philosophy and Practice (e-journal), vol. 4, 2011.

[18] Tusubira F.F., et al., "ICT implementation challenges and strategies for enterprises in Africa," Africa Telecomm, 2001.

[19] Akuegwu B.A., et al., "Information and communications technology (ICT) facilities' utilization for quality instructional service delivery among university lecturers in Nigeria," Review of Higher Education in Africa, vol. 3, 2011. 